\title{
A Comprehensive Adsorption Study of 1-Hydroxy-2-Naphthoic Acid using Cost Effective Engineered Materials
}

Muhammad Aurang Zeb¹, Ghulam Murtaza1, Muhammad Aamer Hussain', Khadija Tul Kubra², Ralph Muvhiiwa ${ }^{3,4}$, Lueta-Ann De Kock ${ }^{3}$, Francis Hassard ${ }^{3},{ }^{4}{ }^{*}$

1. Institute of Soil and Environmental Sciences, University of Agriculture Faisalabad, Punjab, Pakistan.

2. Government College University Faisalabad, Punjab, Pakistan.

3. Nanotechnology and Water Sustainability (NanoWS) Research Unit, University of South Africa, College of Science Engineering and Technology (CSET), UNISA Science Campus, 1710 Roodepoort, Johannesburg, South Africa.

4. Cranfield University, College Way, Bedford, MK43 OAL, UK.

${ }^{*}$ Corresponding author: Francis Hassard (francis.hassard@cranfield.ac.uk)

\section{Abstract}

The naphthoic acids are challenging and costly to remove from water and soil. 1-Hydroxy-2-

Naphthoic acid (HNA) is a phenanthrene decomposition product from petroleum-contaminated environments during the aerobic decomposition of polyaromatic hydrocarbons. The hydrogeological mobility of hydrocarbon breakdown products represent a pollution risk (e.g. for drinking water sources). Adsorption to biochar produced from agricultural by-products is a useful strategy to remediate contaminated wastewaters. Here, we examine the controls on the HNA adsorption to the adsorbents magnetite, clay minerals, biochar and magnetite enriched companion materials, namely the influence of contact time, contaminant concentration and ionization effects at different $\mathrm{pH}$. The adsorption of HNA was investigated using low-cost and readily available adsorbents: i) wheat straw biochar, ii) rice husk biochar, iii) sugarcane biochar, iv) zeolite, v) montmorillonite, vi) magnetite and their enriched magnetic companions. Magnetite 
enriched biochar exhibited greater adsorption rates compared with their nonmagnetic analogs for HNA. The maximum adsorption capacity of the magnetite enriched compounds (initial water concentration of 0.32 mmol HNA.L-1) was 0.45 mmol.HNA.g ${ }^{-1}$ of enriched zeolite. The magnetite enriched biochar and conventional biochar showed similar adsorption kinetics although magnetite enrichment improved the efficacy of adsorption. The adsorption fitted the pseudosecond order model in all cases, suggesting the dominant mechanism of adsorption was chemisorption. The magnetite enrichment reduced intra-particle diffusion, possibly due to fouling or blocking of pores within the particles, as evidenced by the decrease in diffusion rate constants. Overall, HNA adsorption improved after magnetic enrichment due to magnetite competing with inhibition sites on the biochar carriers. These findings translate into equivalence between magnetite and magnetic biochars, suggesting cheaper alternative materials could be synthesized in situ with the biochar acting as both an adsorbent and carrier, increasing the prospect of designer biochars for targeted pollutant removal. This approach has the potential to be used for wastewater treatment or for application as a soil additive for remediation of runoff from contaminated soils.

Keywords: Enriched adsorbents; zeolite; organic pollutants; biochar; 1-Hydroxy-2-Naphthoic Acid; poly aromatic hydrocarbons. 


\section{Introduction}

Inappropriate treatment or disposal of hydrocarbon waste can lead to contamination due to leaching and transport of organic pollutants into the soil matrix (Mao et al., 2015). Organic pollutants come from a variety of sources including wastewaters which are derived from food, leather and textile industries and the petrochemical industry amongst others (Hassard et al., 2015). Petroleum hydrocarbons (PH) are widely found pollutants in soil and contaminated water due to their ubiquity and frequency of use (Qadir et al., 2008). Elevated PH concentrations in industrial wastewater effluents have been reported from low income scenarios (e.g. southern Punjab) and this polluted water is frequently released to the environment without sufficient treatment. Wastewaters containing $\mathrm{PH}$ are also used for agricultural irrigation creating a pathway for contamination of soil (Feenstra et al., 2000) and accumulation within crops, soil and surface water. The accumulation of the $\mathrm{PH}$ pollutants within the tissues or on the surfaces of crops could also promote a human health exposure pathway (Raschid-Sally et al., 2005; Rattan et al., 2005). The $\mathrm{PH}$ are mostly hydrophobic in nature, they are preferentially adsorbed to soil particles, and they can persist within soils for many years. Clean-up of these contaminated soils and treatment of run off wastewater is critical to mitigate environmental human health exposure (Baedecker et al., 1993, Cozzarelli et al., 1994 Das and Mukherjee, 2007). Clearly additional research is required into novel technologies which can remove $\mathrm{PH}$ and their breakdown products.

The breakdown products of $\mathrm{PH}$ are of particular concern as they are predominately polar chemicals, which are readily water soluble, have high hydrogeological mobility and therefore elevated pollution potential for groundwater. 1-Hydroxy-2-Naphthoic acid (HNA) is the first phenanthrene decomposition product in petroleum-contaminated soils during the aerobic decomposition of polyaromatic hydrocarbons $(\mathrm{PAH})$ and is a widely used surrogate for $\mathrm{PAH}$ and 
other breakdown products of $\mathrm{PH}$ (Hanna and Carteret, 2007; Carney et al. 2008). HNA is not just a useful surrogate, it is in itself a compound which needs to be treated to reduce the toxicity of wastewaters. For example, HNA irritates the human respiratory system, causes inflammation of the eyes and skin and can disrupt normal gut function in humans and animals. Several studies have shown HNA as a potent inhibitor of intracellular communication and highlighted a possible role of this compound as a mutagen (Samanta et al., 1999). Quantitative risk estimates for exposure to HNA are not well defined, however oral exposure is considered one route due to consumption of contaminated crops or water. The acute oral Lethal Dose $50\left(L_{50}\right)$ of HNA in rats was $823-1040 \mathrm{mg} \cdot \mathrm{kg}^{-1}$ body weight. The no observed effect level (NOEL) for HNA is considered to be much lower $12-60 \mathrm{mg}^{\mathrm{kg}}{ }^{-1}$ body weight per day (European Chemicals Agency, 2019) suggesting removal of HNA from drinking water and soils through treatment is necessary, particularly in areas prone to high levels of contamination.

Currently, wastewater treatment rely on biological or chemical oxidation processes such as aerobic or anaerobic bio-treatment, ozone or advanced oxidation processes (Rolph et al., 2018). These processes are costly are require significant operation and maintenance investment. A promising route for cost effective remediation of $\mathrm{PH}$ breakdown products is adsorption to natural or engineered adsorbents (Chen et al., 2011). Natural adsorbents are cheaper and more readily available than conventional industrial adsorbents such as granular activated carbon (GAC) and would not require costly regeneration to be effective as additional material can be produced in situ as required. A diverse range of organic and inorganic contaminants (include PH and HNA) can be removed using adsorbents such as magnetite and biochar (Cundy et al., 2008; Lu et al., 2010). Biochar in particular is considered multifunctional and useful for removal of $\mathrm{PH}$ breakdown products from wastewater. Concentration of the pollutant and phase separation (usually water to solid) could facilitate a safe disposal route, for example incineration (Singh et al., 2018). Identifying a suitable material which does not create secondary pollution concerns 
has proved challenging (Hanna and Carteret, 2007). Recent work has shown the propensity of 'designer' or enriched natural materials (where surface area, surface charge or porosity is altered) to target the specific removal of contaminants for removal of organic pollutants such as pesticides or PH (Busquets et al., 2014; Rolph et al., 2018; Rolph et al., 2019). Other natural materials such as the minerals magnetite $\left(\mathrm{Fe}_{3} \mathrm{O}_{4}\right)$, zeolite and montmorillonite which have high surface area and ion exchange capacity to remove a wide range of pollutants / ions from solution (Rashed, 2013). Biochar and iron oxides are readily used separately for the adsorption of organic pollutants however, their interaction effect requires further study under controlled conditions. Our hypothesis was that magnetite enrichment of biochar and clay minerals would enhance the adsorption properties (number and availability of active sites) of natural biochar adsorbents towards HNA for the remediation of contaminated waters. Studies were done to assess the removal of HNA under a variety of adsorption conditions and kinetic modeling was undertaken to assess the dynamic removal rate and permit comparison between materials and suggest the dominant mechanism(s) of adsorption.

\section{Materials and Methods}

\subsection{Chemicals}

1-Hydroxy-2-naphthoic acid, sodium hydroxide $(\mathrm{NaOH})$ both with a purity $\geq 97 \%$ and hydrochloric acid $(\mathrm{HCl})$ were obtained from Sigma-Aldrich (Islamabad, Pakistan). Two types of clay minerals (natural zeolite and montmorillonite), three types of biochars (wheat straw, sugarcane and rice husk biochars) and one iron oxide (magnetite) were used for investigating the sorption of organic pollutants from water. Biochar produced by pyrolysis at $350{ }^{\circ} \mathrm{C}$ were obtained from NARC (Islamabad, Pakistan). Magnetite and natural zeolite were obtained from Meiqi Industry and Trade Co., Ltd (Gongyi City, China) both having a purity of $\geq 99$ percent and particle sizes of 53 and 150 
$\mu \mathrm{m}$ respectively. Analytical grade montmorillonite K30 (1318-93-0) obtained from Sigma Aldrich (UK), having a purity $\geq 99 \%$.

\subsection{Enrichment of biochars and clays with magnetite}

The properties of the magnetite enriched product depend on the enrichment technique and the physical-chemical conditions at which enrichment was carried out. Biochars were produced via pyrolysis of three different feedstocks and the composition, particle and pore size distribution was not controlled as part of this study (i.e. representative of locally available adsorbents). Three magnetite enriched biochars were formed using wheat straw biochar (WSB), sugarcane biochar $(\mathrm{SB})$ and rice husk biochar $(\mathrm{RHB})$ as a base adsorbent. Each biochar was washed three times with deionized water and air dried within a laminar flow hood for at least 24 hours. Subsequently $2 \mathrm{~g}$ of each biochar was mixed with $2 \mathrm{~g}$ of magnetite and a mixed solution was made through addition of $20 \mathrm{~mL}$ of deionized water. The biochar-magnetite mixtures were homogenized using a magnetic stirrer for three hours. Subsequently, sodium hydroxide solution $(0.1 \mathrm{M})$ was added to the magnetite to create a disperse solution of particles which formed a covering layer which was deposited on the surface of each adsorbent particles (visual inspection using microscopy) (Mohan et al., 2014). The functionalized mixture (henceforth enriched compound) was filtered and the residue was washed with buffered deionized water $(\mathrm{pH}$ 7.0). After drying in a laminar flow hood at room temperature, the product of this reaction was stored in air tight bottles. The three mixtures prepared were considered magnetite enriched biochars (WSB, SB and RHB). Enrichment of the clay minerals, zeolite and montmorillonite was carried out as above replacing the biochar with 2 $\mathrm{g}$ each of zeolite, montmorillonite and magnetite in $20 \mathrm{~mL}$ of deionized water. The product was dried at room temperature and stored in air tight bottles. Two mixtures were obtained, magnetite enriched zeolite and magnetite enriched montmorillonite. 


\subsection{Batch experiments}

Batch experiments were performed at ambient temperature $\left(25 \pm 2{ }^{\circ} \mathrm{C}\right)$. Adsorption of HNA was investigated using both original and magnetite enriched biochars (WSB, RHB and SB), clay minerals, (zeolite and montmorillonite) and magnetite. The influence of a number of important process factors were investigated including: contact time of the adsorbent, pollutant concentration and ionization effects at different $\mathrm{pH}$. All samples were filtered $(0.45 \mu \mathrm{m})$ and the adsorption of HNA was measured immediately using a UV-Vis Spectrophotometric (Thermo Electron Corporation, USA) analysis at $340 \mathrm{~nm}$. The HNA concentration obtained from spectrophotometric method was validated against appropriate external quality standards for HNA. Values obtained from the spectrophotometer were corrected based on the absorbance of double deionized water blanks.

\subsection{Adsorption kinetics}

Batch adsorption equilibrium kinetic experiments were carried out in $50 \mathrm{~mL}$ total organic carbon (TOC) free borosilicate glass beakers each containing $25 \mathrm{~mL}$ of solution at ambient temperature. Each experiment was undertaken in triplicate using a HNA solution with a concentration of $0.32 \mathrm{mmolL}^{-1}$ and $0.05 \mathrm{~g}$ of each solid adsorbent material. The beakers were placed on a continuous magnetic stirrer at $200 \mathrm{rpm}$ for a number of time periods $(0,60,180$, 300,600 and $1440 \mathrm{~min}$.), samples were extracted at these time periods using a polypropylene syringe and filter $(0.2 \mu \mathrm{m})$. The kinetic data for all the materials tested was evaluated fitting to the pseudo-first order model, the pseudo-second order model and intra-particle diffusion model. The pseudo-first order model is given by Equation 1 (Ho and McKay, 1998).

$\frac{d q_{t}}{d t}=k_{1}\left(q_{e}-q_{t}\right)$ 
Where $q_{t}$ and $q_{e}$ are the adsorption capacities $(\mathrm{mg} / \mathrm{g})$ at time $t$ and equilibrium respectively and $\mathrm{k}_{1}$ is the pseudo-first order rate constant $(\mathrm{L} / \mathrm{min})$. The linear form of the pseudo-first order model was obtained by integrating and applying the boundary conditions $t=0$ to $t=t$ and $q_{t}=0$ to $q_{t}=q_{t}$ (Equation 2).

$\log \left(q_{e}-q_{t}\right)=\log q_{e}-\frac{k_{1}}{2.303} t$

The pseudo-second order model is given by equation 3 (Ho \& McKay, 1998, 2000)

$\frac{d q_{t}}{d t}=k_{2}\left(q_{e}-q_{t}\right)^{2}$

Where $\mathrm{k}_{2}$ is the pseudo-second order rate constant of adsorption. Integration and applying identical boundary conditions as for the pseudo-first order model gives the linear form of the pseudo-second order model (Equation 4).

$\frac{t}{\left(q_{t}\right)}=\frac{1}{k_{2} q_{e}^{2}}+\frac{1}{q_{e}} t$

The intra-particle diffusion model is given by Equation 5. The different stages of the diffusion process can be identified by linearization of the different portions of the curve given by Equation 5 (Wu et al., 2001)

$q_{t}=f\left(t^{1 / 2}\right)$

\subsection{Adsorption equilibrium isotherms}

Adsorption equilibrium isotherms were investigated using five different HNA pollutant concentrations at equal intervals between 0.02 and $0.32 \mathrm{mmolL}^{-1}$, obtained from a single stock solution of HNA. To investigate the potential for degradation of HNA, five chemical only blank samples (without solid sorbent material) were placed in covered beakers at room temperature for 
3 days (in the dark). These blank samples did not show any loss of HNA during the experiment, suggesting removal was primarily due adsorption of the HNA by the adsorbate. The adsorption equilibrium isotherm was established by adding $0.05 \mathrm{~g}$ each of the solid adsorbent into the HNA solutions having a pH range from 4.5 to 5.3 , followed by shaking in the orbital shaker at a rate of $200 \mathrm{rpm}$ at room temperature for 24 hours. After 24 hours, samples from each of the solutions were collected by filtering through a sterile polypropylene syringe filter $(0.2 \mu \mathrm{m})$. The remaining concentration of the HNA pollutant in each solution was measured using a UV-visible spectrophotometer as above. The capacity $\left(Q_{e}\right)$ of each adsorbent for HNA was calculated according to Equation 6:

$\mathrm{Q}_{\mathrm{e}}=\frac{(C i-C e) V}{M s}$

Where $Q(\mathrm{mmol} / \mathrm{g})$ is the adsorbed amount of pollutant per mass of adsorbent, $C_{e}(\mathrm{mmol} / \mathrm{L})$ is the equilibrium concentration at the end of the experiment, $C_{i}(\mathrm{mmol} / \mathrm{L})$ is the initial aqueous phase concentration, $V(L)$ is the volume of solution and $M_{S}(g)$ is the mass of adsorbent.

\subsection{Effect of pH on adsorption}

Investigation of the effect of $\mathrm{pH}$ on adsorption was carried out using $25 \mathrm{~mL}$ samples of HNA solution $\left(0.32 \mathrm{mmolL}^{-1}\right)$ and $0.05 \mathrm{~g}$ of each solid adsorbent material in batch reactors which were stirred continuously at $200 \mathrm{rpm}$ for 30 minutes. The adsorption at equilibrium was determined at $\mathrm{pH}$ values ranging from 3 to 8 at different time intervals (30-60 min). The $\mathrm{pH}$ ranges were adjusted by using $0.1 \mathrm{M} \mathrm{HCl}$ and $0.1 \mathrm{M} \mathrm{NaOH}$ solutions to the required $\mathrm{pH}$.

An estimate of adsorption was calculated according to Equation 7:

$\%$ Removed $=\frac{C i-C e}{C i} \times 100$ 


\section{Results and Discussion}

The removal of HNA from contaminated water through adsorption is an attractive and low cost method for wastewater treatment (Lu et al., 2010). Here, the adsorption of HNA was investigated using three types of biochar, natural materials, magnetite and magnetic companions conducted under a variety of experimental parameters to simulate the range of expected operating parameters (contact time, contaminant concentration and the ionization effects at different $\mathrm{pH}$ ).

\subsection{Adsorption kinetics}

The adsorption behaviour of adsorbents to HNA was assessed at different time intervals, initially the adsorption occurred rapidly up to 180 min of contact time and then increased more gradually until $400 \mathrm{~min}$. The adsorption of HNA did not continue to any significant degree after $600 \mathrm{~min}$ suggesting saturation of active sites (Figure 1,2) therefore no further HNA adsorption was possible without regeneration of the adsorbents. This adsorption behaviour was the same for all of the adsorbents tested. The removal performance of SB was 4-6\% greater than other biochars from 0 to 60 minutes. The capacities were: $S B=0.43$ mmol.HNA. $\mathrm{g}^{-1}$, for WSB and RHB $=0.42 \mathrm{mmol} \cdot \mathrm{HNA} \cdot \mathrm{g}^{-1}$, after 180 minutes.

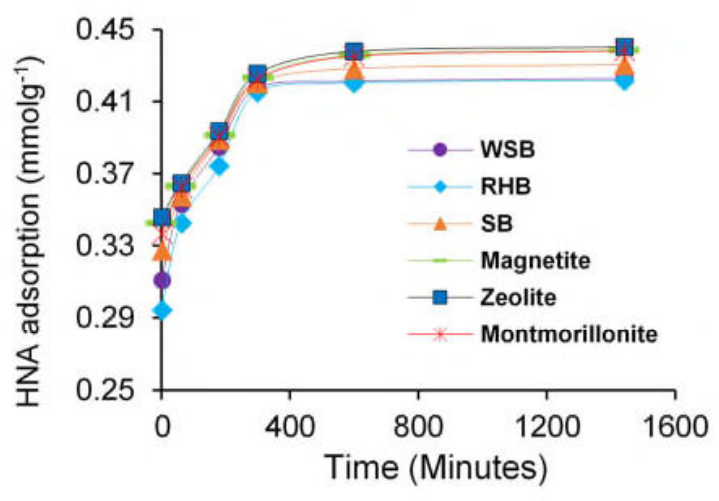

Figure 1) Adsorption kinetics of unmodified adsorbents

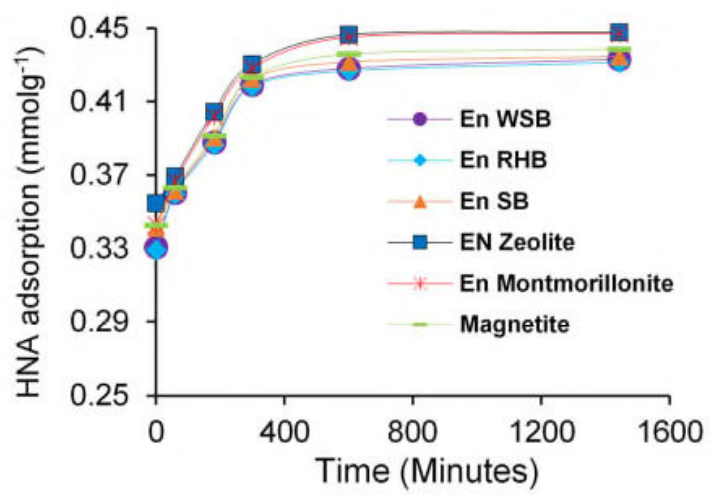

Figure 2) Adsorption kinetics after magnetite enrichment 
After 180 minutes of contact time, the HNA adsorption was similar for magnetite enriched WSB, RHB and SB. The adsorption capacity $\left(Q_{e}\right)$ of the magnetite enriched biochars was 0.43 mmol.HNA.g ${ }^{-1}$. This was several orders of magnitude higher than expected for goethite based natural clay adsorbents which have an adsorption capacity of $\sim 0.009$ mmol.HNA. $\mathrm{g}^{-1}$ obtained from batch experiments which were undertaken in a similar way to this study (Hanna and Carteret 2007). Enrichment using magnetite reduced the heterogeneity in response to the HNA adsorption between the three biochars tested (Figure 1, 2, Table 1). Overall the magnetic SB had a $Q_{e}$ of $0.44 \mathrm{mmol} . \mathrm{g}^{-1}$, this higher value was attributed to elevated adsorption capacity of the SB compared to both the WSB and RHB before enrichment. This is pertinent as the HNA removal character by magnetic biochars was similar to magnetite suggesting this enrichment could be utilized to upgrade the adsorption capacity of local and available biochar. It is theorized that proportionally less magnetite could be utilized (in combination with biochars) to provide similar HNA adsorption performance compared to magnetite. It was considered that using enriched biochars could result in substantial adsorbate cost savings when compared to the use of magnetite as the exclusive adsorbent. The adsorption capacity was in the following sequence and from greatest to least: magnetite $>S B>W S B \approx R H B$ and after enrichment the adsorption capacity increased but was in the same order of performance. For the clay minerals, the adsorption capacity of zeolite, montmorillonite and magnetite were similar at 0.44 mmol.HNA.g ${ }^{-1}$. After enrichment with magnetite, the enriched zeolite and montmorillonite had very similar capacities of 0.45 mmol.HNA.g ${ }^{-1}$. The HNA adsorption capacity in order and from greatest to least was: enriched zeolite $\approx$ enriched montmorillonite $>$ magnetite.

\subsection{Kinetic modelling of HNA adsorption.}

The kinetic data was fitted to the pseudo-first order, pseudo-second order and intra-particle diffusion models (Table 1). All the materials investigated fitted best to the pseudo-second order 
model. This was evidenced by linear correlation coefficient $\left(r^{2}\right)$ values exceeding 0.99 and the closeness of modelled $Q_{e}$ values to the experimental derived $Q_{e}$ values.

Table 1. Kinetic modelling of HNA adsorption to adsorbents

\begin{tabular}{|c|c|c|c|c|c|c|c|}
\hline \multicolumn{2}{|l|}{ Model } & \multicolumn{3}{|c|}{ Pseudo-first order } & \multicolumn{3}{|c|}{ Pseudo-second order } \\
\hline Adsorbent & $\begin{array}{l}\mathbf{Q}_{\mathbf{e} \text { Exp. }}{ }^{*} \\
\text { (mmol.g } \\
\text { 1) }\end{array}$ & $\begin{array}{l}\mathrm{K}_{1} \\
\left(\mathrm{~L} \cdot \mathrm{min}^{-1}\right)\end{array}$ & $\begin{array}{l}\mathbf{Q}_{1 \mathrm{e} \max } \\
\left(\mathrm{mmol} \cdot \mathrm{g}^{-1}\right)\end{array}$ & $\mathbf{r}^{2}$ & $\begin{array}{l}\mathbf{K}_{2} \\
\left.\left.\text { (g.[mmol.min }{ }^{-1}\right]\right)\end{array}$ & $\begin{array}{l}\mathbf{Q}_{\text {2e max }} \\
\left(\mathrm{mmol} \cdot \mathrm{g}^{-1}\right)\end{array}$ & $\mathbf{r}^{2}$ \\
\hline WSB & 0.423 & 0.00415 & 0.0573 & 0.8914 & 0.27919 & 0.425 & 0.9999 \\
\hline RHB & 0.422 & 0.00392 & 0.0573 & 0.8443 & 0.22346 & 0.425 & 0.9998 \\
\hline SB & 0.430 & 0.00507 & 0.0785 & 0.9778 & 0.23391 & 0.433 & 0.9998 \\
\hline **Monto & 0.438 & 0.00783 & 1.5272 & 0.9906 & 0.19642 & 0.436 & 0.9998 \\
\hline Zeolite & 0.440 & 0.00668 & 0.1183 & 0.9976 & 0.20109 & 0.444 & 0.9998 \\
\hline Magnetite & 0.439 & 0.00599 & 0.1067 & 0.9980 & 0.19852 & 0.442 & 0.9998 \\
\hline $\begin{array}{l}\text { Enriched } \\
\text { WSB }\end{array}$ & 0.433 & $\begin{array}{l}0.00484 \\
4\end{array}$ & 0.0896 & 0.9925 & 0.20259 & 0.436 & 0.9998 \\
\hline $\begin{array}{l}\text { Enriched } \\
\text { RHB }\end{array}$ & 0.431 & 0.00507 & 0.0924 & 0.9938 & 0.20821 & 0.434 & 0.9998 \\
\hline $\begin{array}{l}\text { Enriched } \\
\text { SB }\end{array}$ & 0.435 & 0.0030 & 0.0893 & 0.9935 & 0.21556 & 0.438 & 0.9998 \\
\hline $\begin{array}{l}\text { Enriched } \\
\text { Monto }\end{array}$ & 0.447 & 0.00530 & 0.0934 & 0.9817 & 0.19164 & 0.450 & 0.9998 \\
\hline $\begin{array}{l}\text { Enriched } \\
\text { Zeolite }\end{array}$ & 0.448 & 0.00645 & 0.1081 & 0.9948 & 0.20267 & 0.451 & 0.9998 \\
\hline
\end{tabular}

For example, the values of $Q_{2 e m a x}$ was within $0.04 \mathrm{mmol} \mathrm{g}^{-1}$ of $\mathrm{Q}_{\mathrm{eEXP}}$ in all cases. In second order models the rate limiting step to adsorption is considered availability of surface active sites. Removal from solution occurs due to physiochemical interactions between functional groups attached to the solid and chemicals within the water phase (Singh et al., 2018). Good fit to the pseudo-second order model implied that adsorption was dominated by chemisorption processes. Chemisorption is adsorption which involves a reaction between a functional group and the adsorbate (Fierro et al., 2008). In chemisorption dominated sorption processes, there is a strong interaction between the sorbate and the active sites of the adsorbent that results in the formation of new electronic bonds. Regeneration of active sites can be achieved using strong oxidants, 
changes in the $\mathrm{pH}$ or salt concentration. Analysis of the modeled intra-particle diffusion parameters showed that the diffusion of HNA into the adsorbent was fastest for WSB and RHB. The intra-particle diffusion model typically describes adsorption where adsorption rate is dependent on the rate of diffusion of the adsorbent from the external surface of the adsorbent along the pore walls and into the pores of the adsorbent (Wu et al., 2009). The magnetite enrichment of the adsorbents resulted in a small decrease in the initial rate of diffusion into all of the adsorbents (Table 2).

Table 2. Outputs from the intra-particle diffusion model for each adsorbent on HNA

\begin{tabular}{llll}
\hline Adsorbent & $\mathbf{K}_{\text {id }}\left(\mathrm{mmol} .\left[\mathrm{g} \cdot \mathrm{min}^{0.5}\right]^{-1}\right)$ & $\mathbf{B L T}(\mathrm{mmol} / \mathrm{g})$ & $\mathbf{r}^{2}$ \\
\hline WSB & 0.006 & 0.3087 & 0.9914 \\
RHB & 0.0067 & 0.2918 & 0.9849 \\
$\mathrm{SB}$ & 0.0052 & 0.3231 & 0.9759 \\
${ }^{* *}$ Monto & 0.0048 & 0.3316 & 0.9619 \\
Zeolite & 0.0045 & 0.3391 & 0.9345 \\
Magnetite & 0.0045 & 0.3366 & 0.9418 \\
Enriched WSB & 0.005 & 0.3266 & 0.9742 \\
Enriched RHB & 0.005 & 0.3254 & 0.975 \\
Enriched SB & 0.0046 & 0.3087 & 0.9398 \\
Enriched **Monto & 0.0049 & 0.3087 & 0.9667 \\
$\begin{array}{l}\text { Enriched Zeolite } \\
\text { B* Monto = Montmorillonite }\end{array}$ & 0.0044 & 0.3476 & 0.9287 \\
$\begin{array}{l}\text { BLT = Intra-particle diffusion model estimate of hydrodynamic boundary layer thickness which } \\
\text { impacts the diffusion of adsorbent from bulk solution to the external surface of the adsorbent. }\end{array}$
\end{tabular}

The HNA adsorption process can be controlled by a combination of the following: external diffusion to adsorbent, film diffusion on the surface of adsorbent, pore diffusion, surface diffusion 
and adsorption on the pore surface (Tran et al., 2017). Here, the intra-particle diffusion model revealed that the fastest adsorption rates were observed for WSB and RHB evidenced by $K_{\text {id }}$ values of 0.006 and $0.0067 \mathrm{mmol}$.[g.min $\left.{ }^{0.5}\right]^{-1}$ respectfully (Table 2). The addition of magnetite to all materials decreased the initial rate of diffusion into the pores of the adsorbent material, possibly due to partial blocking of the pores for these materials by nano-particles of magnetite (Wu et al., 2009). For example the WSB $K_{\text {id }}$ decreased from 0.006 to 0.005 with similar reductions for other biochar. This observed effect was less pronounced within the other materials which were tested (Table 2). This decrease in rate could possibly be due to a reduction in either the particle pore size or the surface area or availability of active sites (Chen et al., 2011). In rapidly stirred batch systems the diffusive mass transfer can be represented by an apparent diffusion coefficient, which in this case fitted well to the presented experimental sorption rate data. The large positive boundary layer thickness (BLT) values (ranging from 0.2918 to 0.3496 ) indicated that initially the analyte had to diffuse through the aqueous layer surrounding the adsorbent particles (Tran et al., 2017). More rigorous stirring or agitation (shaking) could be used to reduce apparent BLT and potentially increase the rate of diffusion. Here, it was assumed that external resistance to mass transfer was only significant during the initial stages of adsorption, the second slower (and rate limiting) component is the gradual adsorption dominated by intra-particle diffusion (Fierro et al., 2008). Therefore, there was no need to increase mixing speed at the expense of the integrity of the aggregate integrity/ 


\subsection{Adsorption equilibrium isotherm}

At the initial HNA concentration of $0.02 \mathrm{mmol} \mathrm{L}^{-1}$ adsorption was $0.47-0.48 \mathrm{mmol} . \mathrm{HNA}_{\mathrm{g}} \mathrm{g}^{-1}$ for the natural materials studied. All adsorbents had lower HNA amounts adsorbed at elevated contaminant concentrations which implies that full saturation of adsorbents' active sites had occurred preventing further HNA uptake from solution. Therefore adsorption was monolayer and chemisorption could not proceed (Singh et al. 2018). This is due to the decreasing fraction of adsorbed HNA with increasing concentration and is an indication that all of the active sites have been saturated. Magnetite achieved greater adsorption of 0.47 mmol.HNA.g ${ }^{-1}$ compared to SB which had 0.43 mmol.HNA.g ${ }^{-1}$ and WSB which had 0.39 mmol.HNA.g ${ }^{-1}$ (Figure 3, 4). At high concentration ( $\left.0.32 \mathrm{mmol} \mathrm{L}^{-1}\right)$ before enrichment, adsorption efficiency was $0.36,0.36,0.40$ for WSB, RHB and SB respectfully. After enrichment the adsorption efficiency increased to $0.40,0.39$ and $0.44 \mathrm{mmolg}^{-1}$ for WSB, RHB and SB respectfully. Magnetite enriched biochars have higher adsorption capacities as compared to their nonmagnetic analogs, re-enforcing findings of Chen et al., (2011) who showed that hybrid magnetic biochar particles exhibit greater sorption capacity that nonmagnetic analogs.

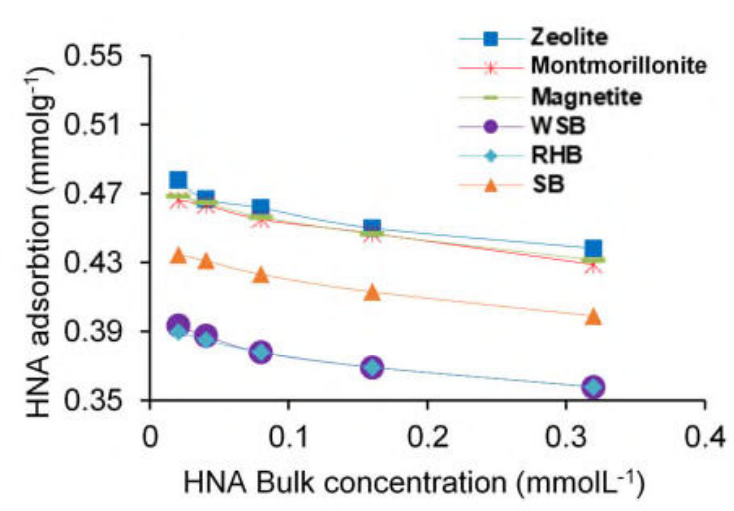

Figure 3) Adsorption isotherm for unmodified adsorbents

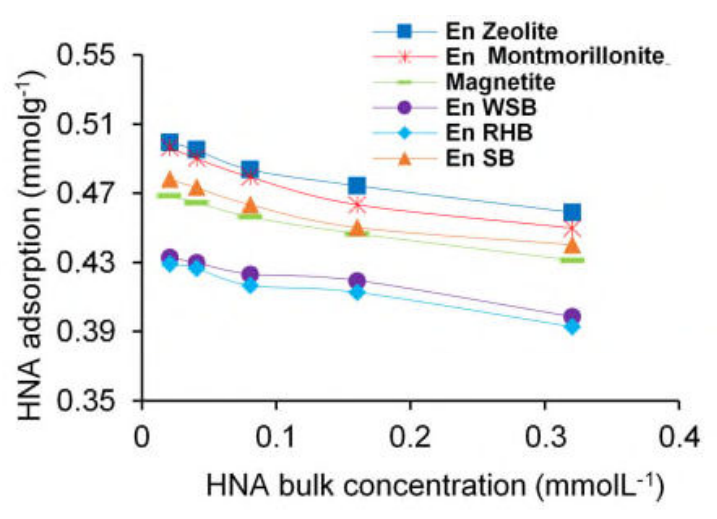

Figure 4) Adsorption isotherm after magnetite enrichment 
Zeolite had $2.3 \%$ greater adsorption than montmorillonite and $1.8 \%$ greater adsorption than magnetite at 0.02 mmol.L-1 (Figure 3). Magnetite enriched clays showed similar uplift in performance figures compared nonmagnetic analogs (Figure 4).

\subsection{Impact of pH on adsorption to biochar}

The $\mathrm{pH}$ is an important factor on the HNA adsorption process, which influences surface complex reactions which occur at specific mineral adsorption sites (Hanna et al., 2010). Previous studies have shown that compounds with stronger electronegativity are bound more strongly to the adsorbent surface which influences the pollutant adsorption rates and regeneration efficacy of adsorbents (Chiou et al., 1979). In this study, the outer surface of the biochar exhibits a diversity of functional groups including: hydroxyl, carboxylic acid and carboxylate. In this study, we controlled the $\mathrm{pH}$ of the solution between 3 and 8 , influencing the protonation or deprotonation of these functional groups (Oh et al., 2012) which in turn influences the ionization of biochar and hence the electrostatic interaction with the HNA adsorptoin. At a pH below the pKa for each functional group on the biochar, the functional group becomes protonated, at a $\mathrm{pH}$ above this threshold, the functional group becomes deprotonated (Lonappan et al., 2018). In this study at a $\mathrm{pH}<5$ the amount of HNA adsorbed increased. This suggested that the electrostatic attraction between the HNA and the protonated functional groups of the adsorbent increased during each decrease in $\mathrm{pH}$. The electrostatic force of interactions, hydrophobic behaviour and pore-filling may be the core factors for adsorption of organic contaminants which includes HNA. The surface layers of biochar studied were considered heterogeneous ( Zhao et al., 2013) this is in part due to bound carbonate and non-carbonaceous components on the surface layers of the biochar (Chen et al., 2008, Cao et al., 2009). Surface pore size was also another important characteristic for the adsorption of organic compounds and has been discussed nil detail within Singh et al. 2018). 
The impact of $\mathrm{pH}$ on adsorption capacity was assessed while maintaining other factors constant: temperature, contact time, adsorbent dose and pollutant concentration. A HNA concentration of $0.32 \mathrm{mmol} \mathrm{L}-1$ with adsorbent dose of $0.05 \mathrm{~g}$ was used for the $\mathrm{pH}$ experiments. Adsorption was greatest at acidic $\mathrm{pH}(3)$ and started to decline at a $\mathrm{pH}<5$ (Figure 5,6$)$. At $\mathrm{pH}>6$ the reduction in adsorption capacity plateaued. At low $\mathrm{pH}$ there was reduced availability of organic anions in solution due to lower hydration, however the ligand exchange at the anionic hydroxyl group also increases at low pH (Polubesova et al., 2010). This study was based on anion exchange capacity as aqueous $\mathrm{HNA}$ releases $\mathrm{H}^{+}$ion from the $\mathrm{COOH}$ ligand and there is a negative charge on the COO of HNA. The combination of the anionic form of HNA alongside the increased anionic exchange capacity of the absorbent resulted in a greater tendency for exchange of the adsorbent's anion with the HNA anion. For most adsorbents tested the highest capacity was observed when the adsorbents particles were positively charged and the carbonyl functional groups of HNA was negatively charged at $\mathrm{pH}$ value $<5$ (Table 3). As the adsorbent and adsorbate became negatively charged at high $\mathrm{pH}$, repulsion between them occurred. A similar adsorption behaviour of several organic acid complexes on the oxide surface has been observed previously (Nilsson et al., 1996, Evanko and Dzombak, 1999).

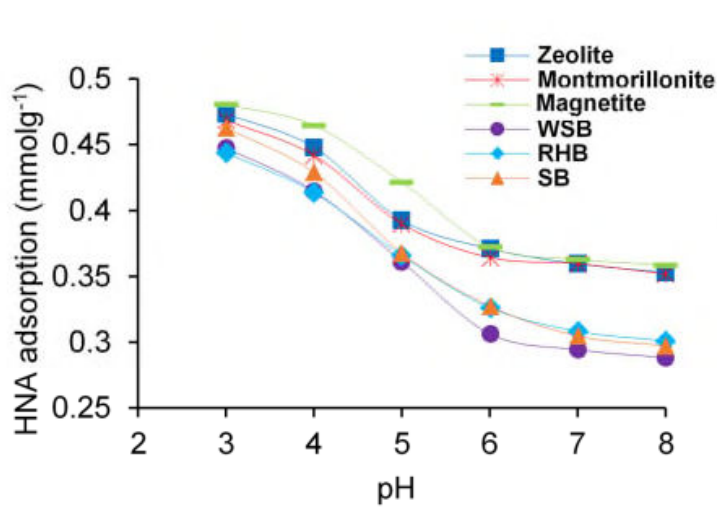

Figure 5) Effect of pH on HNA adsorption to un-modified natural adsorbents

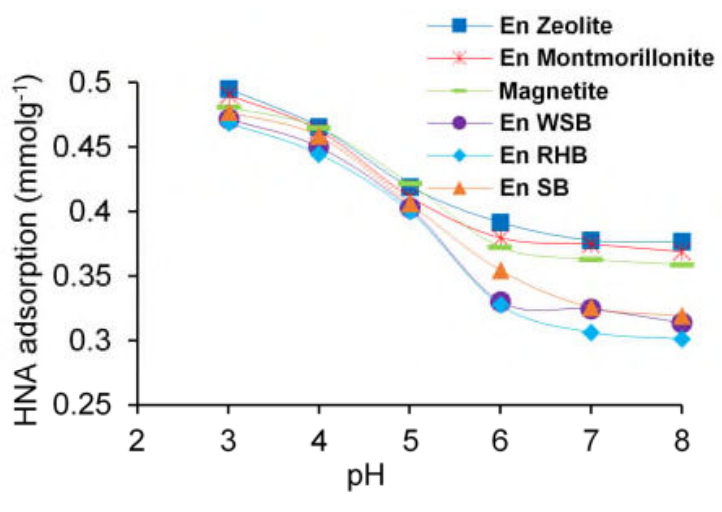

Figure 6) Effect of $\mathrm{pH}$ on HNA adsorption after enrichment of natural adsorbents with magnetite 
In this study, the removal efficiency of HNA by the clay minerals was greater than the biochar adsorbents. The greater adsorption by the clay minerals is probably due to the greater surface area available for the clays and therefore active sites present on the surface of the adsorbent. Biochar showed a pronounced decrease in HNA adsorption before enrichment as compared to clay and magnetite adsorption but after enrichment the adsorption behaviour of magnetic biochar decreased more gradually, similar to clay and magnetite for $\mathrm{pH}$, time and concentration of contaminant. The adsorption tendency of biochar is low for anionic contaminants due to its more negatively charged surfaces (Beesley and Marmiroli, 2011; Mukherjee et al., 2011) and thus engineered biochar enhanced by the magnetite modification process facilitates magnetite availability on the surface of the carrier solid. It was demonstrated that after enrichment adsorption performance was increased due to the combined effects to enhance the adsorption capacity for anionic contaminants. Magnetite has a synergistic effect toward adsorption, as the reduction of $\mathrm{Fe}^{+3}$ to $\mathrm{Fe}^{+2}$ provides a free electron, also non-covalently bonded $\mathrm{Fe}^{+3}-\pi$ interactions. Zeolite has a higher adsorption threshold level compared to other adsorbents as the anion exchange capacity (AEC) of zeolite was greater than clays or biochar. Further experimental studies could optimize the impregnation to facilitate maximal surface area to volume of absorbent / carrier material.

This study has demonstrated a strong approach for the removal of HNA from contaminated water and it has been revealed from the study that clay minerals and magnetite have greater sorption efficacy compared to other adsorbents which are commonly used. It was also indicated that enrichment has a serious and positive impact on adsorbents and their surface properties toward adsorption of pollutants. Further work could investigate the influence of point of zero charge on HNA adsorption and undertake column tests to assess the adsorption using realistic volumes of real water with environmentally relevant concentrations of pollutants. Further diagnostics of internal structure of magnetic biochars would be of benefit for further optimisation of this technology. 


\section{Conclusions}

The batch adsorption data demonstrated that HNA adsorption occurred rapidly before gradual removal occurred which stopped after all the active sites were saturated. The HNA adsorption character fitted the pseudo-second order model for all materials tested including enriched and conventional companions, suggesting chemisorption dominated the removal mechanism. Enrichments created magnetic nanoparticle suspensions with amorphous biochar complexes. This study applied the intra-particle diffusion model which showed that despite modest improvements to HNA removal efficiency, the magnetite reduced the effective intra-particle diffusion, possibly due to fouling or blocking of pores within the particles as evidenced by lower boundary layer thickness for enriched as opposed to normal companion materials. The blinding effect of magnetite to the biochars was offset by the performance improvements for HNA removal. The removal of HNA was better at lower $\mathrm{pH}$ with values of 5-6 being critical for enhancing the activity of key functional groups to reaction with HNA. Magnetic enrichment increased the adsorption of HNA by competing with inhibition sites. These findings translate into equivalence between magnetite and magnetic biochars, suggesting cheaper alternative materials (to magnetite in isolation) could be synthesized in situ with the biochar acting as a carrier material. These findings are of interest to waste and water treatment practitioners interested in low-cost solutions for removal of organic pollutants and their breakdown products.

\section{Acknowledgements}

The authors are grateful to Professor Ravi Naidu for insightful suggestions on the manuscript. The authors acknowledge funding provided by the Rutherford Fund Strategic Partner Grant, (RF2018-66) to Francis Hassard. Lueta De Kock is grateful for funding provided by the National Research Foundation of South Africa (Grant Numbers 111002) 


\section{References:}

Azizullah, A., M.N.K. Khattak, P. Richter and D.P. Hader. 2011. Water pollution in Pakistan and its impact on public health. A review. Environ. Int. 37: 479-497.

Baedecker, M.J., I.M. Cozzarelli, R.P. Eganhouse, D.I. Siegel and P.C. Bennett. 1993. Crude oil in a shallow sand and gravel aquifer 3. Biogeochemical reactions and mass balance modeling in anoxic groundwater. Appl. Geochem. 8: 569-586.

Beesley, L., E. Moreno-Jiménez, J.L. Gomez-Eyles, E. Harris, B. Robinson and T. Sizmur. 2011. £. Environ. Pollut. 159: 3269-3282.

Benjamin, M.M. and J.O. Leckie. 1981. Multiple-site adsorption of $\mathrm{Cd}, \mathrm{Cu}, \mathrm{Zn}$, and $\mathrm{Pb}$ on amorphous iron oxyhydroxide. J. Colloid Interface Sci. 79: 209-221.

Busquets, R., Kozynchenko, O. P., Whitby, R. L., Tennison, S. R., and Cundy, A. B. 2014. Phenolic carbon tailored for the removal of polar organic contaminants from water: A solution to the metaldehyde problem? Water Res., 61, 46-56.

Cao, X., L. Ma, B. Gao, W. Harris. 2009. Dairy-manure derived biochar effectively sorbs lead and atrazine. Environ. Sci. Technol. 43: 3285-3291.

Carney MW, Erwin K, Hardman R, Yuen B, Volz DC, Hinton DE, and Kullman SW. 2008. Differential developmental toxicity of naphthoic acid isomers in medaka (Oryzias latipes) embryos. Mar. Pollut. Bull. 57:255-266.

Castelo-Grande, T., P.A. Augusto, P. Monteiro, A.M. Estevez and D. Barbosa. 2010. Remediation of soils contaminated with pesticides: a review. Int. J. Environ. Chem. 90: 438467.

Chen, B., Chen, Z., and Lv, S., 2011. A novel magnetic biochar efficiently sorbs oganic pollutants and phosphate. Bioresour. Technol., 102, 716-723.

Chen, B., D. Zhou and L. Zhu. 2008. Transitional adsorption and partition of nonpolar and polar aromatic contaminants by bio-chars of pine needles with different pyrolytic temperatures. Environ. Sci. Technol. 42: 5137-5143.

Chiou, C.T., L.J. Peters and V.H. Freed. 1979. A physical concept of soil-water equilibrium for nonionic organic compounds. Sci. 206: 831-832.

Cozzare Ili, I.M., M.J. Baedecker, R.P. Eganhouse and D.F. Goerlitz. 1994. The geochemical evolution of low-molecular-weight organic acids derived from the degradation of petroleum contaminants in groundwater. Geochem. Cosmochem. Acta. 58: 863-877. 
Cundy, A.B., L. Hopkinson and R.L.D. Whitby. 2008. Use of iron-based technologies in contaminated land and groundwater remediation: A review. Sci Total Environ, 400: 42-51.

Das, K. and A.K. Mukherjee. 2007. Crude petroleum-oil biodegradation efficiency of Bacillus subtilis and Pseudomonas aeruginosa strains isolated from a petroleum-oil contaminated soil from North-East India. Bioresour. Technol., 98: 1339-1345.

European Chemicals Agency 2019. Accessed online 04.10.2019 [https://echa.europa.eu/substance-information/-/substanceinfo/100.001.522]

Evanko, C.R. and D.A. Dzombak. 1999. Surface complexation modeling of organic acid sorption to goethite. J Colloid Interface Sci. 214: 189-206.

Fierro, V., Torné-Fernández, V., Montané, D., and Celzard, A. 2008. Adsorption of phenol onto activated carbons having different textural and surface properties. Microporous and Mesoporous Materials,111(1-3), 276-284.

Gomes, H.I., C. Dias-Ferreira and A.B. Ribeiro. 2013. Overview of in situ and ex situ remediation technologies for PCB-contaminated soils and sediments and obstacles for fullscale application. Sci. Tot. Environ. 445: 237-260.

Hanna, K. and C. Carteret. 2007. Sorption of 1-hydroxy-2-naphthoic acid to goethite, lepidocrocite and ferrihydrite: Batch experiments and infrared study. Chemosphere. 70: 178186.

Hanna, K., B. Rusch, L. Lassabatere, A. Hofmann and B. Humbert. 2010. Reactive transport of gentisic acid in a hematite-coated sand column: experimental study and modeling. Geochem. Cosmochem. Acta. 74: 3351-3366.

Hassard, F., Biddle, J., Cartmell, E., Jefferson, B., Tyrrel, S., and Stephenson, T. 2015. Rotating biological contactors for wastewater treatment-A review. Process Saf. Environ. 94, 285-306.

Ho YS and Mckay G, 1998. A Comparison of chemisorptions kinetic models applied to pollutant removal on various sorbents. Process Saf. Environ. 76:4, 332-340.

Ho YS and Mckay G, 2000. The kinetics of sorption of divalent metal ions onto sphagnum moss peat', Water Res. 34:735-742.

Lonappan, L., Roussi, T., Brar, S.K., Verma, M. and Surampalli, R.Y., 2018. An insight into the adsorption of diclofenac on different biochars: Mechanisms, surface chemistry, and thermodynamics. Bioresour. Technol. 249, 386-394.

Lu, M., Z. Zhang, W. Qiao, Y. Guan, M. Xiao and C. Peng. 2010. Removal of residual contaminants in petroleum-contaminated soil by Fenton-like oxidation. J. Hazard. Mater. 179: 604-611. 
Mao X, Jiang R, Xiao W and Yu J. 2015. Use of surfactants for the remediation of contaminated soils: A review. J. Hazard. Mater. 285:419-435.

Mukherjee, A. Zimmerman, A.R. and Harris, W, 2011. Surface chemistry variations among a series of laboratory-produced biochars. Geoderma 163: 247-255.

Mohan, D., Kumar, H., Sarswat, A., Alexandre-Franco, M., and Pittman Jr., C.U., 2014. Cadmium and lead remediation using magnetic oak wood and oak bark fast pyrolysis biochars. Chem. Eng. J. 236, 513-528.

Nilsson, N., P. Persson, L. Lovgren and S. Sjoberg. 1996. Competitive surface complexation of o-phthalate and phosphate on goethite $(\alpha-\mathrm{FeOOH})$ particles. Geochem. Cosmochem. Acta. 60: 4385-4395.

Oh, S.Y., H.W. Kim, J.M. Park, H.S. Park and C. Yoon. 2012. Oxidation of polyvinyl alcohol by persulfate activated with heat, $\mathrm{Fe}^{2+}$, and zero-valent iron. J. Hazard Mater. 168: 346-351.

Polubesova, K., Eldad, S and Chefetz, B, 2010. Adsorption and oxidative transformation of phenolic acids by Fe (III)-montmorillonite. Environ. Sci. Technol. 44: 4203-4209.

Qadir, A., R.N. Malik and S.Z. Husain. 2008. Spatio-temporal variations in water quality of Nullah Aik-tributary of the river Chenab, Pakistan. Environ. Mon. Assess. 140: 43-59.

Rashed, Mohamed Nageeb. "Adsorption technique for the removal of organic pollutants from water and wastewater." In Organic pollutants-monitoring, risk and treatment. IntechOpen, 2013.

Rolph, C. A., Villa, R., Jefferson, B., Brookes, A., Choya, A., Iceton, G., and Hassard, F. 2019. From full-scale biofilters to bioreactors: engineering biological metaldehyde removal. Sci. Tot. Environ. 685, 410-418.

Rolph, C. A., Jefferson, B., Hassard, F., and Villa, R. 2018. Metaldehyde removal from drinking water by adsorption onto filtration media: mechanisms and optimisation. Environ. Sci.: Wat. Res., 4(10), 1543-1552.

Samanta, S.K., A.K. Chakraborti and R.K. Jain. 1999. Degradation of phenanthrene by different bacteria: evidence for novel transformation sequences involving the formation of 1-naphthol. Appl. Microbiol. Biotechnol. 53: 98-107.

Singh, N.B., Nagpal, G., Agrawal, S., and Rachna, 2018. Water purification by using Adsorbents: A Review. Environ. Technol. Innov. 11, 187-240.

Tran, H.N., You, S-J., Hosseini-Babdegharae, A., and Chao, H-P., 2017, Mistakes and inconsistencies regarding adsorption of contaminants from aqueous solutions: A critical review, Water Res., 120: 88-116. 
Uzair, M., M. Ahmed and K. Nazim. 2009. Effects of industrial waste on seed bank and growth of wild plants in Dhabeji area, Karachi, Pakistan. Pak. J. Bot. 41: 1659-1665.

Wu F-C, Tseng R-L, and Juang R-S, 2009. Initial behavior of intraparticle diffusion model used in the description of adsorption kinetics', Chem. Eng. J., 153: 1-8.

Zhao, L., Cao, X., Mašek, O., and Zimmerman, A., 2013, Heterogeneity of biochar properties as a function of feedstock sources and production temperatures, J. Hazard. Mater. 256-257, 19. 